\title{
O lugar, a teoria e a prática profissional do médico: elementos para uma abordagem crítica da relação médico-paciente no consultório
}

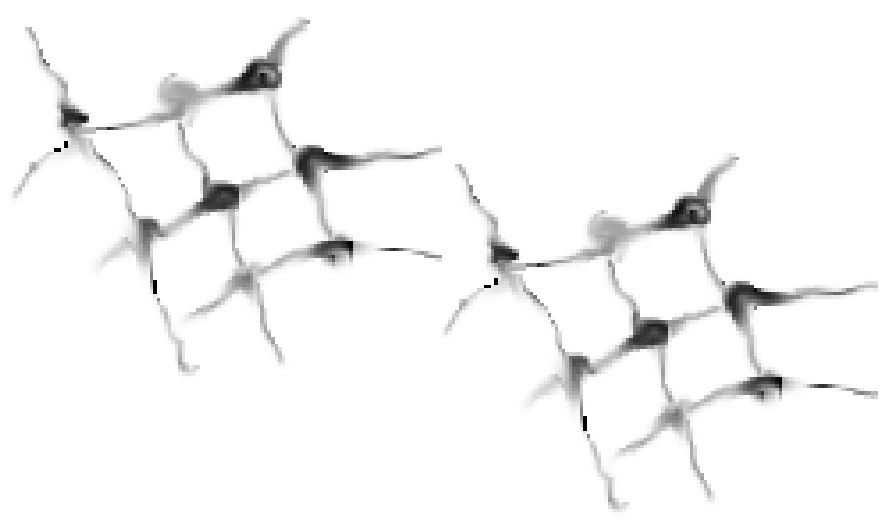

Giovanni Gurgel Aciole

ACIOLE, G. G. The place, theory and professional practice of the physician: elements for a critical approach to doctor-patient relations in the consulting room, Interface - Comunic., Saúde, Educ., v.8, n.14, p.95-112, set.2003-fev.2004.

The doctor-patient relation is discussed in this paper based on three analytic elements: 1) the consulting room as a place where what occurs, predominantly, is medical practice; 2) the scientific rationality of the biological mold that shapes the near-totality of the theoretical basis of this know-how; and 3) the structural and circumstantial issues that organize the professional practice of physicians. Assessing this relation within the context of the central dimension of medical practice, the author indicates that overcoming the boundaries defined by these elements calls for a different kind of professional practice and for the broadening of its theoretical basis, so as to establish a relationship between the physician and his patient based on a different value and a different meaning.

KEY WORDS: Doctor-patient relations; Medicine; Health; societies; conducts in medical practice.

A relação médico-paciente é aqui discutida a partir de três elementos analíticos: 1) o consultório como lugar onde se exerce, predominantemente, a prática do médico; 2) a racionalidade científica de matriz biológica que conforma a quase totalidade das bases teóricas deste saber fazer; 3) as questões estruturais e conjunturais que organizam a prática profissional do médico. Propondo considerar esta relação numa dimensão central para a prática médica, aponta-se que a superação dos limites colocados por esses elementos deve se dar por meio de uma outra prática profissional e do alargamento de suas bases teóricas, que acabem por constituir um outro valor e significado para o encontro entre o médico e seu paciente.

PALAVRAS-CHAVE: relações médico-paciente; Medicina; Saúde; sociedades; condutas na prática dos médicos.

${ }^{1}$ Professor do Departamento de Medicina Social e Preventiva da Faculdade de Medicina da Pontifícia Universidade Católica de Campinas (FM/Puccamp); Presidente do Sindicato dos Médicos de Campinas e região (Gestão 2003-2006). <aciolegg@terra.com.br> 
O lugar e os elementos teórico-práticos da prática médica

O lugar por excelência do acontecimento da clínica é o consultório médico. Independente da forma pela qual se objetive, ou do setor de produção em que se localize - se sob a gestão estatal nos serviços públicos, ou sob a forma de atividade liberal, autônoma - neste lugar, a clínica assume contornos de prática individual e privada, isto é, representa um modo singular de intervenção que, embora assentada em matrizes explicativas de natureza coletiva, se exerce na solidão do corpo individual.

A prática clínica ao se deslocar do consultório para outros espaços como o hospital, em suas enfermarias, adquire outras feições, que não cabe aqui comentar, embora também lá conserve substancialmente o aspecto técnico do saber fazer médico. No hospital, entretanto, a prática clínica fica mais empobrecida em sua função relacional, dado que, neste lugar, se consuma a completa sujeição do paciente, reduzido liminarmente à condição passiva de objeto.

o consultório médico é, pois, o lugar de realização de uma prática clínica, espaço onde ela se realiza, ou ainda o lugar em que o procedimento de consulta, ali praticado, encontra possibilidades de realização. Sob esta condição, o consultório se apresenta como o espaço de localização, e de explicitação, de um saber fazer, o do médico, que utiliza uma disciplina, a semiologia.

Esta disciplina (no sentido foucaultiano) diz respeito à arte da apreensão dos sinais $e$ sintomas observáveis aos sentidos e é composta de dois momentos: uma linguagem propedêutica - a anamnese - e uma ferramenta diagnóstica - a semiotécnica. A primeira parte consiste na realização de um interrogatório dirigido à obtenção de informações ordenadas sobre o paciente cujo raciocínio lógico se baseia numa taxonomia de doenças. Este arranjo taxonômico estabelece um significado para o conjunto de informações colhidas e, por sua vez, define uma linha de procedimentos para a intervenção clínica na direção da cura e/ou da proteção à saúde.

A segunda parte se refere à perfeita e adequada utilização dos sentidos, como o tato, a visão $e$ a audição, em procedimentos como palpação, percussão e ausculta, que buscam acrescentar, aos elementos colhidos na etapa anterior da consulta, outras informações que corroboram ou redirecionam o raciocínio taxonômico iniciado pela anamnese, mas que guardam com a primeira intrínseca relação, uma vez que tanto ordena possível novo interrogatório como é ordenado por este.

No momento de acontecimento da clínica, é que se realiza, ou deveria de realizar, o encontro de duas subjetividades, a do médico e a do seu paciente. Este último constitui o objeto de trabalho do saber fazer médico, que se ancora e se inicia, na necessidade de um diálogo, ainda que seja o diálogo induzido pela interrogação da anamnese. Não obstante, esta é uma situação liminar que exige o refúgio num espaço particular, o consultório, indispensável na construção de uma relação de poder - antes um poder fazer, poder operar.

Este momento, por sua vez, traz duas condições imprescindíveis para uma situação dialógica de fato, que estão presentes no exercício da prática clínica e, em particular, na relação entre médicos e pacientes. Uma destas condições é a da ciência, isto é, um certo modo de se dar a conhecer alguma coisa sobre a realidade, que se desdobra num contínuo e complexo conhecimento. Fundada cientificamente, a prática médica demanda a necessidade de qualificação específica de extenso e complexo conhecimento científico.

Há algo, contudo, que a faz separar-se dos demais trabalhos técnicos e científicos: o imperativo moral, peculiar a sua ética corporativa, que implica uma sabedoria incomum no uso tanto dos conhecimentos quanto dos valores de conduta e que, por isso mesmo, necessita de uma segunda condição: a arte.

Arte como capacidade de apreensão e síntese mediada pelos sentidos e de talentosa criatividade de proceder tecnicamente por intermédio de uma ética adequada, ou seja, a 
capacidade de elaborar uma tecnologia do afetivo no científico, muitas vezes tomada como humanismo, em que ouvir, receber, interessar, confortar, orientar são formas de dispor ações técnicas derivadas da ciência (Schraiber, 1993).

Arte, porém, que não logra atingir a função apontada por Fischer (1987), para quem esta concerne sempre ao homem 'total' e o capacita a identificar-se com a vida dos outros, a incorporar a si aquilo que ele não é, mas tem possibilidade de ser. Arte enquanto signo de transcendência: permanentemente datada segundo um recorte histórico, porém imanente como manifestação específica do gênero humano e só a ele possível de realizar e apreender.

No encontro do consultório há, além disso, duas distintas subjetividades. São, porém, oriundas de interesses divergentes, e em duas situações antagônicas, que devem dialogar: um sujeito, portador de necessidades que colocam em xeque sua condição de normalidade; outro sujeito, doador de possibilidades, cientificamente dadas e aprovadas, para a superação e o retorno à condição de higidez. Na situação de um encontro desta natureza, habita uma necessidade: encontrar a saída possível e desejável, dada por uma (re)direcionalidade, agora conjunta, que agregue as subjetividades do usuário e do médico num processo de interação comumente denominado de relação médico-paciente.

Esta relação, construída, assentada e baseada nesta conjunção - de base subjetiva constituir-se-ia por um conjunto de necessidades e elementos a que se somariam as capacidades aprimoradas de intervenção resolutiva, portanto, de forte concretitude e objetividade. Esta capacidade aprimorada é dada pelo apoio material $e$ instrumental agregado pelo desenvolvimento científico e tecnológico, gerador de novos produtos e equipamentos capazes de aprimorar a capacidade diagnóstica e terapêutica da intervenção médica, tanto quanto de novos e maiores conhecimentos dirigidos à obtenção de um padrão de qualidade de vida, e de uma maior certeza acerca da capacidade humana de superar seus limites na sua eterna luta de adaptação às condições hostis da sobrevivência.

Sob tais elementos e complexidade, habita no consultório esse encontro contínuo e tenso entre necessidades e capacidades!

As variáveis que medeiam a relação entre o paciente e o médico Além destas condições assinaladas - os binômios ciência/arte e técnica/moral - há as mediações colocadas por variáveis que interferem na construção de uma conjugação favorável entre as subjetividades do médico e do paciente. Passemos, pois, às considerações sobre algumas variáveis envolvidas nesta relação, que têm, de um lado, o avanço inegável do eixo ciência-tecnologia a ampliar a capacidade de solução de problemas e, de outro, a sensação de desamparo $e$ insegurança verificada no plano dos indivíduos e coletivos atendidos. Mediações que permitem, por exemplo, a constatação da inadequação do conjunto dos serviços de saúde, públicos ou privados, de resolverem os problemas de saúde, quer no plano individual, quer no coletivo. Constatação ainda mais paradoxal diante dos avanços científicos em torno dos problemas de saúde e de suas soluções, do desenvolvimento de 
um arsenal tecnológico existente e disponível em serviços equipados para suas intervenções. Esta situação gera e reforça um sentimento de desproteção do cidadão comum. Tanto mais pungente quanto aquele cidadão comum reclame da falta de interesse e de responsabilização dos diferentes serviços em torno de si e de seu problema de saúde (Merhy, 2002).

A primeira variável é o saber fazer médico. Este representa o conjunto de conhecimentos estruturados que permitem sua reprodução e utilização (consumo) pelo usuário, com conseqüente definição de um valor de uso para a intervenção médica $e$, deste modo, a legitimação da prática médica no espaço social. Este conjunto de conhecimentos e técnicas é composto: pelas Ciências Biológicas (Biologia Molecular, Genética, Microbiologia), pelas Ciências Morfofuncionais (Anatomia, Fisiologia e Patologia), e pelos saberes instrumentais tecnológicos oriundos da Semiologia, da Patologia Clínica e da Imagenologia (Luz, 1987).

O fato de ter forte base nas Ciências Biológicas faz com que este conjunto de saberes e instrumentos constitua para a Medicina uma prática profissional armada e intervencionista que extirpa o problema que se localiza em parte específica do corpo como um mal externo a ser debelado $e$ curado. Esta concepção representa o senso comum do que é a profissão no imaginário social e encontra, no consultório, o espaço, o lugar da prática médica por excelência, alimentador e reforçador da mesma.

Outra variável nesta questão é o próprio paciente, o indivíduo no qual se exerce o saber fazer médico para legimitação do uso do saber médico: substrato sob o qual se produz um enorme valor de uso para a ciência médica. Para a relação em exame, o paciente acaba como o pólo passivo sobre o qual se opera uma transformação produzida pelo médico. Definamo-lo, pois, como aquele que tem a possibilidade de tornar-se, a quem quase nunca cabe um poder operar. A necessidade do paciente de ser transformado, por outro lado, é recortada, e significada, a partir da capacidade de objetivação do saber fazer médico, em grande medida, negadora de sua subjetividade, o que acaba por reduzir aquele a sua dimensão biológica.

Cabe considerar, ainda, que o termo paciente ganha uma denominação prismática sob a qual ficam compreendidas várias situações significativas, a destacar a já mencionada, de alguém sobre quem se exerce o poder (potencial) de vir a ser, de se transformar. Desta forma, podemos denominar "pacientes" todos aqueles que fazem utilização habitual de um dado bem ou serviço público ou coletivo, ou de fregueses ou clientes.

Estes significados remetem-nos a planos de relação distintos. No primeiro caso, o termo usuário remete aos serviços de produção do cuidado individual e coletivo sob a ótica do direito de cidadania, cujo acesso vem sendo marcado pela idéia de direito social, de natureza igualitária e coletiva. Já clientes ou fregueses, remetem aos mecanismos pautados pela ótica jusnaturalista do direito individual, porém, ajustado em relações de mercado, de compra $e$ venda de serviços, numa livre competição entre consumidores e produtores, tomados como iguais e em situação de simetria.

Esta distinção configura uma certa dicotomia de Estado e mercado, público $x$ privado, que é fortemente arraigada no senso comum (Aciole,

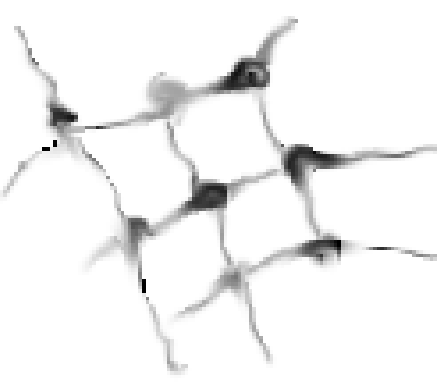


1999). Não pode, contudo, fazer obscurecer a idéia de que, seja no setor público seja no setor privado, os pacientes devem ter necessidades específicas reconhecidas e atendidas. Entre estas pode ser considerada a garantia de acesso a tecnologias compatíveis com a complexidade do seu 'problema' de saúde e/ou obter 'escuta' e atenção singular a sua pessoa por um profissional ou por uma equipe de saúde com a qual produza vínculos (Cecilio \& Matsumoto, 2000).

Este usuário/cliente pode, ainda, apresentar-se perante os serviços com diferentes demandas. Uma é a demanda por cuidado, pela solução de um problema de saúde, uma necessidade básica de cuidado ou intervenção cuidadora. Outra, é a do usuário que comparece para solicitar procedimentos de natureza administrativa como emissão de um atestado de saúde, certificado, declaração ou similar, e no qual não se verifica alteração digna de cuidado, ou cuja situação de normalidade não está posta em risco. Uma terceira possibilidade é a do usuário que se apresenta na forma de um coletivo, grupo ou instituição, como creche, escola, associação etc., para a qual se pode considerar as duas demandas anteriores, necessidade de cuidado específico e/ou de procedimentos normativos administrativos. Uma quarta situação é a do usuário que se apresenta sob representação, como o do conselheiro de saúde local ou municipal. Este, tanto pode reclamar atenção para si, quanto para aqueles que representa, o que lhe dá uma complexidade, na qual a sobreposição de papéis lhe confere uma múltipla identidade.

Estas situações apresentadas querem ressaltar a necessidade de diferentes níveis de diálogo, quando muitas vezes se adota uma postura rígida $e$ inflexível que não conjuga diferentes tempos gramaticais e lingüísticos, semântica e semioticamente, somente considerando a abordagem uma dimensão do contato. Contato matizado pela linguagem utilizada, de predomínio temático focado na doença, tomada em seu aspecto "naturalizado" e, assim, biologizado. Podemos dizer, parafraseando Marcuse (1980), que a comunicação realizada, nos serviços de saúde, em geral, e nos consultórios, em particular, padece de uma redução unidimensional: a linguagem médica biologizada unidimensionalmente.

Convém destacar a importância das determinações de natureza ecohômica, ideológica, cultural e política que interferem nesta questão, apontando a construção de estruturas mercadológicas, com segmentação $e$ exclusão de contingentes populacionais do acesso e consumo de serviços $e$ teenologias, bem como da gestão estatal posta a serviço de lógicas delimitadoras de infraestruturas de baixa e alta densidade tecnológica ou de políticas focalistas ou universalistas.

Há, neste sentido, uma ausência de diálogo profícuo entre os médicos e seus pacientes - poderíamos dizer entre os trabalhadores da saúde e os pacientes - uma vez que os primeiros parecem perdidos num ponto eqüidistante entre o cliente e o usuário. Estas duas condições referem-se às supostas condições de atendimento no espaço privado, lugar do cliente, e no espaço público (estatal), lugar do usuário (Aciole, 1999). Aliás, a distinção de 'privado' e 'público' segundo diferenciais de qualidade é cada vez mais difícil, se olharmos aspectos como produção de segurança, satisfação dos 
usuários, vinculação e responsabilidade, ou mesmo, resolutividade (Aciole, 2000).

Outro forte aliado para a ausência de uma relação dialógica entre o médico e o paciente encontra-se, a nosso ver, na mediação de um processo de gestão do trabalho que, ao correlacionar de modo anacrônico a produção e a remuneração - numa equação que correlaciona custo e benefício - dá, a esta última, aspecto de retribuição de merecimento a partir da relação tempo versus produção, em que pese não ter uma vinculação direta. Sendo unicamente uma exploração de força de trabalho numa fração contratada de tempo, contabilizada em horas de jornada disponível.

Assim, a gestão acaba restrita, na maioria dos casos, a serviço de prover as condições necessárias ao mínimo de interrupções do processo de trabalho, numa perspectiva de cunho essencialmente taylorista. Com isso, submerge sua potencialidade de atuação no desenvolvimento do trabalho solidário $e$ crítico, e do planejamento da oferta de serviços. Ganha, desta forma, uma lógica estritamente quantitativa, quase nunca qualitativa; fiscalizadora nunca apoiadora; controladora - nunca avaliadora.

No setor público, ademais, uma especificidade da gestão diz respeito aos seus imperativos de atender a uma "saúde pública", aqui entre aspas para se referir ao seu objetivo institucional de organizar a prestação da assistência nos serviços mantidos pelo Estado. Nestes combinam-se a tarefa de ampliar a cobertura para a população mais carente e excluída com o atender aos imperativos de uma extensão de cobertura a custos compatíveis a que o desenvolvimento econômico dos países periféricos possa suportar, estendendo a assistência médica, talvez, de uma forma mais simplificada $e$ barata do que gostaríamos de encontrar (Donnangelo, 1976).

Esta lógica de gestão, incorporada ao senso comum como emblemática do espaço público, apresenta-se, por outro lado, matizada no espaço dito privado, posto que este é fruto de uma intensa segmentação do mercado da assistência à saúde. Nesta condição, vamos ter uma competição acirrada em que a disputa por uma clientela cada vez mais restrita tem provocado, ao contrário do que apregoa a regulação pela competitividade, uma queda acentuada na qualidade dos serviços prestados.

Em que pese o bombardeio da opinião pública de que é o contrário, a relação entre os agentes do trabalho médico e seus empregadores é marcada pelo conflito entre expansão mercadológica na captação de clientelá e adoção de mecanismos de regulação de custos/benefícios. Situação resultante da intensiva incorporação de tecnologia agregadora de valor de capital e de valores de uso e que permite extrair maior mais valia sobre o trabalho médico. E já se desloca fortemente na direção da captura do processo de trabalho, em seu aspecto mais direto que é a relação médico-paciente, por mecanismos oriundos de uma reestruturação produtiva traduzida em propostas como a do managed care e que já se implanta fortemente nos setores complementares à assistência pública (Merhy, 2002).

Finalmente, mas não por último, é preciso considerar, como outra variável o paradoxo entre os avanços científicos - tanto em termos de conhecimentos quanto de soluções - em torno dos problemas das pessoas $e$ das comunidades, e até da existência de serviços altamente equipados para 
estas intervenções, $e$ o sentimento de desproteção que acomete o cidadão comum, especialmente na área da prestação de serviços de assistência, sejam públicos sejam privados (Merhy, 1997a).

Concordamos com este autor, quando reconhece que os usuários de saúde desejam um trabalho clínico centrado neles, e que o trabalho médico é um arsenal poderoso de práticas clínicas, não exclusivas, contudo, pois, de uma maneira ou de outra, todos os trabalhadores de saúde fazem clínica (Merhy, 1997b). Mas é justamente o caráter desta possibilidade de fazer clínica que gostaríamos de pôr em discussão.

Qual clínica? Quando interrogamos acerca disto, temos em mente que a $\sum_{-1}$ referência daquele autor aponta, muito provavelmente, para o potencial inventivo de uma atenção centrada na escuta da singularidade e na preocupação cuidadora às necessidades dos pacientes. O que quer dizer uma clínica de sujeitos, quaisquer que sejam, desde que criadores, em si e para os ontros. Condição que requer a singularidade de um espaço de consulta: o consultório.

Antes, porém, receamos uma generalização da atitude médica mais geral, num fortalecimento do atual conceito de clínica, e de sua prática objetivadora, produtora de insegurança. Caso predomine esta atitude como o modo paradigmático da intervenção junto aos, e nos, pacientes, contrariando a manifestação reformuladora que faz aquele autor, continuaremos imersos no imenso paradoxo de ampliar as promessas tecnológicas de produção de longevidade e de intervenção na doença, enquanto aprofundamos a sensação de insegurança que acomete os indivíduos a quem se faz tais promessas.

Refletir, então, sobre as possibilidades de construção de uma outra clínica é a tarefa a que devemos nos entregar! Um ponto de partida, por isso mesmo, pode ser buscado no exame crítico das fundamentações teóricas que nos conduziram até o momento.

\section{A teoria que conduz a uma prática "objetivadora" do trabalho médico}

Quando dizemos que o saber médico realiza a "objetificação" do paciente, fazemo-lo pelo reconhecimento de uma abordagem centrada na dimensão biológica do indivíduo. Ao fragmentar, ainda que artificialmente, o complexo corpo humano, em frações histológicas, anátomo-funcionais ou sistêmico-fisiológicas, a clínica médica, especialmente a atual, abstrai de si os demais planos de relações que reúnem e interligam estas partes num todo, $e$, com isso, produz a redução do homem à condição de objeto, transformando-o em coisa manipulável sobre a qual se intervém com medidas prescritivas ou invasivas.

Neste processo, anula, ou faz desaparecer a dimensão subjetiva de tal "coisa", transformando-a num simulacro do real, visto que cinde a relação dialética subjetivo-objetivo, realizadora do sujeito. E o justifica alegando a necessidade de um distanciamento crítico para o juízo diagnóstico, falacioso eufemismo de neutralidade. Uma vez que mencionamos a cisão da relação dialética sujeito-objeto, vamos nos referir ao pensamento marcusiano no que se refere à compreensão da relação intrínseca entre eles, 
particularmente quando aborda esta questão a partir da análise das formulações feitas por Hegel.

Marcuse (1988) aponta-nos que Hegel, em sua ontologia, afirma a existência de uma estrutura universal da totalidade do ser e define que, diante disso, o ser seria, então, um processo: aquele pelo qual uma coisa "compreende" ou "se apodera" dos vários estados de sua existência, levandoos à unidade, mais ou menos duradoura, do seu em-si, constituindo-se, pois, como a mesma, através de toda mudança. Tudo o que é, existe, em maior ou menor grau, como um sujeito. Para Marcuse (1988), portanto, sempre segundo o pensamento hegeliano, a verdadeira existência só começa quando o estado imediato passa a ser compreendido como negativo, quando os entes tornam-se sujeitos e lutam por adaptar seu estado aparente as suas potencialidades.

O processo dialético, diz-nos, tem sua força motivadora na pressão para superar a negatividade; processo num mundo no qual o modo de existência dos homens e das coisas é engendrado por relações contraditórias: assim, cada conteúdo particular só se expande ao mudar-se no seu oposto. Este último é parte constitutiva do primeiro, e o conteúdo do todo é a totalidade das relações contraditórias nele implicadas.

Logicamente, a dialética começa quando o entendimento humano reconhece ser incapaz de apreender alguma coisa de modo adequado por meio das formas qualitativas ou quantitativas pelas quais a coisa é dada. $O$ verdadeiro ser de alguma coisa surge como sendo diferente de si mesmo: existe, como no seu ser-outro.

Em outras palavras, tudo o que existe só é real na medida em que atua num processo de relações contraditórias que constituem sua existência. $\mathrm{O}$ sujeito deve, pois, ser considerado como uma espécie de revelação de suas intrínsecas contradições. Assim, por exemplo, uma pedra é uma pedra $e$ somente será alterada por uma força extrínseca que modifique seu 'existir', por exemplo, uma picareta ou uma força mecânica que a desloque no lugar; muito diferente é uma planta que existe, isto é, se desenvolve por si mesma, $e$ já traz na forma de uma semente as condições potenciais que assumirá ao existir. Deste modo, uma pedra é um contínuo processo de ser uma pedra, mas uma planta existe totalmente no processo de semente, flor até a destruição.

No caso do homem, este processo é ainda mais complexo, pois este é o único ser vivo que tem 'conhecimento' de seu próprio desenvolvimento; isto é, o entendimento de poder determinar sua auto-realização, de suas potencialidades e seus limites; seu vir a ser é o resultado do processo de sua adaptação à vida, em que repousa suas ações de trabalho e labor na produção da vida, e a razão só existe através da realização deste processo de ser (Marcuse, 1980).

Com base nestas formulações, e para Marcuse (1980), a teoria hegeliana é considerada uma filosofia "negativa" porque seu racionalismo levava a uma crítica do que até então havia sido tido como verdade. As reações em contrário apontavam-na como capaz de reconhecer as potencialidades das coisas, mas incapaz de conhecer sua realidade.

Para fazer frente a esta filosofia, que submete a realidade à razão 
transcendental, esboçou-se, principalmente com Auguste Comte, o que veio a se chamar de filosofia positiva, ou posivitismo em sua acepção moderna: concepção de compreender e estudar os fenômenos do mundo como objetos neutros, governados por leis universalmente válidas. Assim, opondose a interpretar os fatos como o trabalho, histórico, do homem, a filosofia positiva estudava-os segundo os modelos da natureza $e$ sob o aspecto da necessidade objetiva.

Esta contra-ofensiva foi reforçada pelo grande progresso verificado, especialmente nas Ciências Naturais, a partir da metade do último século até nossos dias, e também por ter logrado êxito em sua pretensão de conduzir à integração de todo o pensamento humano, influenciando, assim, os vários campos do saber, notadamente as Ciências Sociais e Humanas, em particular, as derivadas da Biologia (Marcuse, 1988).

É neste estatuto do "positivo" que se ancora e estrutura todo o desenvolvimento e elaboração do pensamento clínico, notadamente no estatuto científico que recebe a Medicina. Esta, a partir de um enorme desenvolvimento, normaliza, disciplina e organiza as regras "universais" de produção e reprodução do saber fazer médico, até o ponto em que se pode, inclusive, reconstruir arqueologicamente seu nascimento, como fez Foucault (1994). Este, ao reconstruir os passos dados para a consolidação da clínica moderna, acaba por demonstrar a importância dos avanços da patologia, que elucida e localiza lesões e distúrbios fisiopatológicos, como fundamentais para a construção e consolidação da semiologia como forma de linguagem da clínica moderna.

Sob este paradigma organiza-se a estrutura curricular da formação em Medicina, de modo que na trajetória de vir a ser médico, o aluno vai ser inicialmente apresentado ao silêncio do cadáver a dissecar, e consumirá os dois primeiros anos de sua formação na apropriação dos diferentes planos anátomo-funcionais biológicos. Como etapa intermediária, o estudante será apresentado a uma rica taxonomia de sinais e sintomas, tomada numa linguagem específica, a semiologia, cujo valor de uso lhe permite compreender, significar e intervir, sobre um corpo - agora vivo, mas que continua a se manifestar pelo silêncio dos órgãos que o médico vê, apalpa, percute e pressiona.

Finalmente, este corpo será estilhaçado numa interminável variedade de disciplinas que formatam e organizam o saber interventor e que desconstrói o corpo humano em seus vários órgãos, sistemas e aparelhos, cada qual definindo uma especialidade que delimita seu campo de abrangência a partir de uma suposta integração dos vários sistemas e aparelhos: integração que só se daria nos planos abstratos de um lugar inexistente, e que responde pela fragmentação da prática médica que, por sua vez, formata a própria escola médica (Santos, 1998).

É assombrosa a capacidade desta Medicina clínica que se constitui no segundo paradigma da História da Medicina (Foucault, 1994). A partir dela constrói-se seu objeto como um saber sobre o individuo, mas tomado como corpo doente que exige uma intervenção que dê conta desta sua singularidade, abstraída dos demais planos da realidade. Esta é a base da chamada Medicina científica e tecnológica atual, erigida nos pilares do 
positivismo científico (Schraiber, 1993; Aciole, 2000).

Distante está, portanto, esta clínica de possibilitar acesso ao ser, como sujeito, limitando-se a recortar imagens estáticas, momentos, fragmentos corpóreos deste processo e a reificá-las como verdade, estabelecida pela referência às leis universais imutáveis e a-históricas. Um momento marcante desta forma de proceder foi aquele no qual se estabelece uma história "natural" da doença, ou seja, em que se estabelece o objeto da prática médica, acima e fora da dimensão imanente ao ser humano. Aqui mais uma vez, também em decorrência deste modus operandi, verificamos a ausência de uma relação dialógica entre o médico e o paciente, já que o primeiro nada mais faz do que 'dialogar' com a doença que habita o corpo do segundo, $e$ com ela interage, articula, define, recorta e estabelece sua ação. E não com o sujeito que a porta, que se torna mero instrumento de acesso à doença!

Geneticamente, podemos localizar a origem da ausência desta relação dialógica no processo de formação médica - outra variável - já que se trata de um processo centrado na dimensão biologicista (Santos, 1998). Esta dimensão não apenas se ramifica em todos os desmembramentos posteriores de superespecializações, mas é também, central à formação de todos os demais saberes correlatos desmembrados a partir da clínica médica, como as outras profissões da saúde.

Este processo de formação da maneira como está estruturado, buscando explicitação de uma dimensão mensurável, constitui a primeira das grandes alienações que perpassam e condicionam o processo de produção do cuidado à saúde, por meio do instrumental clínico, centrado numa dimensão positivista que conduz à perda da dimensão crítica envolvida na produção dos indivíduos/sujeitos de sua ação e de sua vida. Processo de alienação que vai ser bem explorado, por exemplo, por Canguilhem (1990) cuja obra se ergue na defesa de que as fronteiras entre o normal e o patológico, entre o ser saudável e o ser doente, serão mais facilmente compreendidas se tomadas, não isoladamente, mas como um todo.

A superação deste quadro requer uma profunda reforma no processo de formação do médico, que passa pela afirmação de que a construção de uma outra escola médica é tanto desejável quanto imperativa. Resta fazer, à luz das condições atuais, esta transformação possível e definir como e quando acontecer (Aciole \& Merhy, 2003).

A 'alienação' do trabalho e a organização da prática médica Próximo passo, nesse percurso crítico da relação médico-paciente (e, por extensão, da própria prática médica), é o de analisarmos a concepção de alienação de Marx. Para este (no que, aliás, empresta de Hegel que, por sua vez, o atualiza de Rousseau), é pelo trabalho que o homem vence a separação entre os mundos objetivo e subjetivo; transforma a natureza em um meio adequado ao seu próprio desenvolvimento; satisfaz suas necessidades vitais básicas. É o trabalho que permite exteriorizar nossa capacidade criativa e inventiva, tem forte dimensão ontológica, isto é, produtora de homens (Marx, 1983). Ou numa linguagem hegeliana, o trabalho objetiva o subjetivo, o sujeito se reconhece como produtor do objeto. 
Para que o trabalho se torne alienado, é preciso que a divisão social do trabalho, imposta pelo capitalismo, pela expropriação dos meios de produção do trabalhador, faça com que os indivíduos trabalhem para outros como se para a sociedade e para si mesmos. Assim, reificado, tornado objeto, o trabalhador aliena para o capital a sua força de trabalho, que se torna mercadoria destinada a produzir mercadorias, ou seja, o próprio trabalhador se torna mercadoria (Marx, 1983).

Tal situação produz uma outra: a impossibilidade de o trabalhador se reconhecer naquilo que produz, que aparece como uma coisa externa, pronta em si mesma, dura como a pedra. Igualmente, as condições impostas pelo capitalismo são tais que obrigam o trabalhador a vender sua força de trabalho por um preço muito inferior ao trabalho que realiza, colocando o produto do trabalho fora do alcance do próprio trabalhador. É a este tríplice distanciamento que Marx denomina de alienação do trabalho: este se torna "outro", alheio ao trabalhador, e deste para si mesmo (Marx, 1983).

Este processo de expropriação do trabalhador produzido pelo capitalismo tem, ainda segundo Marx (1983), sua gênese facilitada pela produção de um exército de reserva o que impede ou delimita um nível baixo de poder reivindicador dos trabalhadores, ao mesmo tempo em que reduz ao mínimo o valor de sua força de trabalho no mercado. A organização da prática médica tem sofrido este fenômeno por meio da multiplicação desenfreada de escolas médicas, nos anos setenta e oitenta do último século, desequilibrando o mercado na direção dos baixos salários.

Ocorre então, o que é uma constatação cada vez mais comum, o esgotamento da Medicina como uma prática liberal. No caso médico, isto é resultado do fato de que a organização de sua prática tem sido afetada pelas transformações do modo de produção introduzidas pelo capitalismo moderno. Tal transformação traz a perda da dimensão liberal desta prática $e$ a submete, cada vez mais, ao processo de expropriação dos meios de produção, transformando o médico num trabalhador. No sentido marxiano, significa que o médico é cada vez mais um produtor de trabalho que oferece a venda de sua força no mercado em troca da obtenção de uma renda, muitas vezes na forma de salário (Donnangelo, 1976; Schraiber, 1987), em que pese sua reiterada resistência e franca adesão ideológica ao status quo que lhe assegura a sociedade capitalista (Campos, 1988; 1992).

Este processo tem se estruturado em torno da progressiva incorporação tecnológica ao trabalho médico, afastando-o da posse material de seus meios de produção, até o ponto em que ganha características muito específicas numa reengenharia tecno-produtiva, que vai remodelando menos a base tecnológica da própria Medicina e mais o território dos processos relacionais dos atos de saúde e das práticas que governam estes atps produtivos, na direção de que o trabalho vivo em saúde se veja quase tơtalmente capturado pelo trabalho morto: no caso caras e complexas mercadorias como equipamentos e máquinas que prometem saúde, mas mais trazem insegurança (Merhy, 2002).

A esta política deliberada, associam-se as sucessivas crises econômicas, em que o modelo concentrador de renda produz o conseqüente deslocamento da profissão do exercício liberal como atividade central de captação de 
recursos via clientela individual. De modo que, hoje, o assalariamento é uma importante, senão principal, via de entrada da categoria no mercado de trabalho.

No entanto, a classe médica ainda "sonha" com a clientela privada e com a manutenção de um status quo, presa a uma perspectiva romântica passadista que desconsidera a inexorável transformação da sociedade, na qual se organiza um mercado de trabalho e de consumo, produto $e$ produtora das sobre-determinações que interagem em seu processo de constituição como corporação profissional, por sua vez, imersa numa teia complexa de situações na qual se busca, e se obtém, o acúmulo de diversos vínculos empregatícios: mera forma compensatória do processo de expropriação de que acabamos sendo vítimas e agentes (Aciole, 1999). Nesta trama, em particular, o setor público vai significar, para o médico, um lugar de baixa valorização ideológica, em que seu trabalho ganha dimensão de "bico": forma ainda mais compensatória de reagir à expropriação da condição liberal que advoga possuir esta corporação (Aciole, 1999).

Em grande medida, a persistência deste ideário de sobrevivência encontra seu lugar no processo que acompanhou a explosão de escolas médicas, no Brasil, no interior do qual estas incorporaram as diretrizes flexnerianas para a formação médica e para sua estruturação organizacional. Estas diretrizes estavam consoantes com as necessidades sociais ditadas pelo modelo capitalista em desenvolvimento, bem como em consonância com os avanços científicos legitimados, de então. Isto significou o encontro sinérgico entre sua dimensão de prática técnica que se estruturava de acordo com as características de uma prática social, e a racionalidade que fundamentava esta mesma prática social como direcionada para a construção e consolidação do modo de produção capitalista. Trazer a educação médica para a modelagem científica significou adotar, para aquela, os recortes imanentes dados para a condição de prática técnica: especialização do trabalho $e$ fragmentação do saber (Aciole \& Merhy, 2003).

Estes têm sido os pilares e os marcos da educação médica, que marcam a complexa relação entre a Medicina $e$ a sociedade, com o adicional de que o século $X X$ revelou o esgotamento deste modelo. Seja porque se esgotou de fora, com as teorias críticas expurgando um certo exagero do centramento da razão; seja porque se esgotou de dentro, pelo próprio esgotamento de uma certa modalidade de expansão científica na qual produz parte de si na forma de tecnologia/equipamentos (Aciole, 2000).

A este esgotamento associam-se as crises do modo de produção capitalista, resultantes dos antagonismos e conflitos sociais que vão sendo produzidos e mitigados, pela lógica do capital em sua trajetória histórica. Neste contexto, a Medicina tem sido justamente criticada no modo como vem se realizando tecnologicamente, agregando crescentes e estratosféricos custos, quer a tomemos do ponto de vista individual, quer como prática técnica fundante da saúde pública, sem com isso aumentar proporcionalmente sua capacidade resolutiva ou mesmo realizar suab promessa, muitas vezes implícita, de produzir saúde e felicidade (Aciole \& Merhy, 2003).

Além disso, como prática técnica e social, a Medicina produz um processo 
de trabalho específico: a prática médica. O processo de trabalho é aqui entendido como sendo, em geral, o modo como se organiza o saber fazer para objetivar resultados e, portanto, o modo pelo qual os conhecimentos, as normas e as técnicas se organizam ao longo do tempo em atividades que possibilitam a interação entre profissionais de saúde e usuários gerando o consumo de recursos materiais, de conhecimentos e de tecnologias, produzindo o consumo dos serviços de saúde e produzindo a sensação de saúde.

No caso específico, o trabalho em saúde é determinado pelo saber fazer médico, que como já é fragmentário e compartimentado, tem esse caráter capturado pelo próprio processo, a ponto de o trabalho se tornar, outra vez, alienante. Isto também acontece porque os diferentes modos de competência profissional geram a exclusividade de cada segmento, que se legitimam na produção de atos, que são os procedimentos, cujo compromisso é com a perfeição da técnica em si, e com o pressuposto de que sua somatória compõe um padrão de assistência, de que decorre a luta fratricida pela afirmação de atos corporativos e joga as corporações num processo abstraído do contexto social em que atuam, vendo-se como práticas técnicas exclusivamente.

Neste processo, mascaram-se, ou perdem-se de vista, as implicações sociais que tais práticas também possuem e fica quase impossível reconhecer a realidade de alienação (no sentido dado por Marx) que o capital tem produzido sobre o trabalho médico, tendo a este como mais uma mercadoria produtora e reprodutora de mercadorias. Condição, aliás, a que pode ser relegado o ato médico (Aciole, 2003).

Fruto desta somatória de fatores resulta, conseqüentemente, um trabalho cada vez mais alienante, produtor e reprodutor daquela sensação de insegurança, a que já aludimos, e duplamente alienado: na sua substância e na sua prática.

Em direção a uma outra relação médico-paciente É deste modo, duplamente alienados, duplamente eqüidistantes, que produzimos nossa grande contribuição para a ausência da relação dialógica com nossos clientes, ou pacientes. E esta contribuição reside no modus operandi com que vimos exercendo nosso saber fazer.

Ao se render incondicionalmente à supremacia compartimentadora que o avanço tecnológico trouxe de modo incomensurável à prática do saber fazer, nós, médicos, acabamos por colocar a penúltima pá de cal na possibilidade transformadora da clínica e aniquilamos seu espaço, transformando o consultório numa espécie de entreposto mercadológico entre os nossos pacientes e nossas máquinas maravilhosas. E o reforçamos, dedicando-nos, em imensa maioria, a centrar esforços para acumular habilidades no uso da tecnologia armada, hipervalorizando a supremacia tecnológica, saudada como paradigma absoluto de modernidade, esquecidos, alienados, ou submissos às determinações de interesses da cadeia produtiva, na qual nos inserimos como agentes da voz ativa e da voz passiva.

Esta atitude explica em grande parte, por exemplo, a intensa desvalorização do acontecimento da clínica, que é a consulta, e, por 
extensão, do seu lugar - o consultório. Ainda que seja pelos condicionantes da gestão externa sobre ela, mas, igualmente, porque a categoria vem tratando a consulta clínica como um momento menor, subvertendo seu potencial criativo e instaurador de uma relação que se pretende, e se constrói, no diálogo entre subjetividades.

Esta desvalorização encontra manifestação, por exemplo, no fato de que nos sistemas de remuneração do processo de trabalho, quer na esfera pública quer na privada, este seja o momento de menor valor específico, $e$ que se expressa no pagamento de pouco menos de três reais no Sistema único de Saúde ao procedimento de consulta médica simples.

Este esvaziamento também produz o chamado serviço raso do pronto atendimento, ditado pelo binômio 'queixa-conduta'. Neste tipo de serviço estão ausentes tanto a exploração de características psicossociais, culturais $e$ familiares dos pacientes, quanto a reconstrução das suas condições de vida. Não se volta para qualquer finalidade que não seja a de tomar a 'queixa' como inteiramente derivada do estatuto ontológico que tem, para o médico, a doença, e de colocar aquela como fio condutor de escolhas terapêuticas (Mendes-Gonçalves, 1986).

Tal prática significa uma clara expressão da adesão do profissional médico ao processo de expropriação da clínica, aliada à estruturação de um serviço de baixíssima resolutividade, cujo único produto é o de gerar lucro para os sistemas farmacêuticos e laboratoriais, pela produção desenfreada de exames laboratoriais desnecessários e a indução ao consumo, legal, de fármacos prescritos de modo automático e mecânico.

Este processo de expropriação da arte na ciência médica e de dupla alienação da prática chega a provocar a redução na procura pela formação em áreas do saber fazer médico de baixíssimo poder de agregar custos à consulta, como a Pediatria. Esta especialidade tem seu centro nas orientações de puericultura e no acompanhamento clínico de pouca invasividade, gerando baixa utilização de exames ou procedimentos de mais alto custo, assim denominados por utilizarem maciçamente propedêutica armada ou invasiva de alta incorporação de tecnologia/equipamento.

A reiterante alusão à subjetividade envolvida na relação médico-paciente decorre de que a consideremos uma relação tocada muito profundamente por uma dimensão cuidadora - dimensão que deveria subsumir o consumo de recursos e tecnologias como doadora de sentido para o existir da profissão. Vale ressaltar, do mesmo modo, nossa recusa em resvalar para um certo "psicologismo subjetivista" ou mesmo advogar caráter prescindível ao aporte tecnológico gerado pelo desenvolvimento científico. Pois isso seria negar as contribuições deste progresso científico para a certeza diagnóstica $e$ para as alternativas terapêuticas, e até mesmo para o enfrentamento de patologias, com maior grau de eficácia e eficiência. Significaria, ainda, em última instância, apregoar uma romântica e saudosista volta ao passado, nem tão distante assim cronologicamente, em que as medidas heróicas quase sempre transtornavam mais o doente do que a doença em si.

Tampouco pretendemos constituir aqui um argumento na direção de uma guinada estritamente filosófica, de modo a conduzir o ensino e a prática da clínica a um plano epistemológico de limites e contornos 


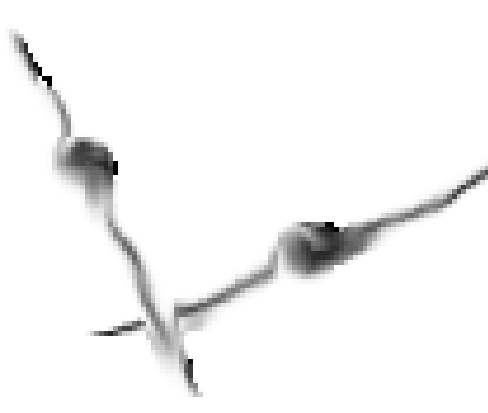

imprecisos. Antes, convém reconhecer que a objetificação do paciente até seja uma necessidade da eficácia do procedimento terapêutico, o que coloca a necessidade de uma reflexão mais profunda acerca desta questão.

Todavia, pretendemos mergulhar na discussão suscitada por Santos (1999), ao propor a busca de caminhos para a construção de um novo saber fazer na clínica, quando menciona as propostas de Campos (1992) e Merhy (1997b). O primeiro, propõe uma clínica ampliada, ou uma clínica da singularidade na qual cada caso é um caso, mas que consegue dialogar e incorporar criticamente outros saberes e diretrizes, incorporando, por conseguinte, preocupações com o vínculo, a resolutividade e a responsabilização. O segundo propõe uma clínica subordinada às tecnologias leves, para propiciar acesso a linhas de fuga, em que os agentes do trabalho médico permitiriam a aparição do trabalho vivo. Isto é, de um agir portador de uma potencialidade e criatividade voltada para a produção de mudanças $e$ rearranjos nos seus processos de trabalho que tome a relação com o paciente/usuário/cliente numa direção totalizante. E que esta relação, principal doadora do sentido para esta mesma prática, seja construída constantemente em ato.

Em seus comentários, Santos (1999) acredita que o desafio para a construção de uma clínica ou outra, ou ambas, sem que se limitem a ampliar a superfície de registro e controle, reside na produção de novos conhecimentos autônomos que dêem um novo sentido para a clínica. Sentido este que invada o saber fazer que se produz e, com a força de um instituinte, tome a forma de um novo senso comum.

Mas o que seriam estes conhecimentos autônomos doadores de um novo sentido para a clínica? Acreditamos que um passo inicial para esta ruptura $e$ esta invasão do senso comum está em que se inicie urgentemente um movimento de revalorização do acontecimento clínico, a consulta, e o seu lugar, o consultório, dando-lhe um outro significado e uma outra direcionalidade na busca de se fazer espaço, também, para a subjetividade, produtora de conhecimento e de autonomia.

Isto implica um duplo movimento: um, interno, de alargamento da prática fragmentária até seu oposto totalizante, pela incorporação crítica, todavia, de outros saberes mais voltados para este ângulo do "ser", produzido no senso comum. Dito de outro modo, isto equivale a um movimento de significar a Medicina como "arte" mais do que como ciência absoluta. Contudo, tal significação representa menos um mergulho no campo do empirismo e do desenvolvimento de uma aptidão 'natural' e mais um movimento dialético de tornar-se um ser-outro, o seu negativo. Um outro, portador de um movimento externo ao lugar que, tendo em vista a recuperação do sentido da prática médica, se coloque em defesa da vida Atitude que a todo instante requer uma ação constitutiva de um novo sujeito, o sujeito médico.

Para fazê-lo é preciso começar por investir no consumo de um tempo maior para o exercício daquela fração de arte contida no ato do interrogatório e do exame físico, sempre lembrando a velha máxima de que a clínica é soberana e de que uma anamnese e um exame bem feitos já solucionam a grande maioria dos casos, porque respondíveis à necessidade 
básica humana de ser ouvido e reconhecido na condição de sujeito portador de singularidades. Para tanto, faz-se necessária uma retomada, ou uma aproximação profunda, com outras linguagens igualmente potentes para a elucidação diagnóstica, de conseqüência resolutiva, ancoradas nos saberes da psicologia, psicanálise e sociologia, por exemplo, mas também com a linguagem verbal, ilocucionária, ou pictórica.

Tal medida teria o fim de, continuamente, refundar a clínica enquanto um saber estruturante de um ferramental de técnicas e saberes, e fundante de um novo olhar sobre o indivíduo. Dissemos de técnicas, não essencialmente de tecnologias! Tecnologias leves, não duras! Condição necessária para a aproximação eficiente e eficaz, facilitadora e construtora de uma relação na qual dialoguem subjetividades e se construa reciprocamente um compromisso de intervenção sobre um organismo, visto muito além de sua dimensão biológica, embora este seja o substrato de excelência onde o saber fazer médico opera sua legitimação.

Para produzir trabalho vivo em ato, como quer Merhy (1997a), necessita, enfim, o médico superar os liames objetivos de seu trabalho alienado, emprestando a si o verdadeiro significado social de buscar as transformações na cadeia produtiva de insumos e equipamentos que tratam, enfim, a saúde como mercadoria, para devolver a esta a plenitude dos modos de andar a vida, $e$ a capacidade de constituir normalidades.

Ao deslocar o centro de gravidade da intervenção médica, na sua relação com os pacientes, para o consultório e para uma maior produção de tecnologia leve, cremos possível tornar-se o médico um sujeito com maior autonomia em relação à propriedade de seus meios materiais e, portanto, menos dependente de sua captura pelo capital. Para tanto, seu saber fazer, sua semiologia, deve ter incorporados novos signos e sinais, ampliando-lhe a superfície de registro e controle de sua clínica, a partir do mergulho, inclusive, numa perspectiva dialética crítica, que incorpore o "negativo", como o vir-a-ser, o que torne quase impossível sua transformação em trabalho morto, ou sua fetichização em mercadoria (Merhy, 2002).

É como movimento organizado, que a categoria médica pode romper com o vaticínio de sua adesão ao capital, em grande medida negadora da dimensão ontológica do trabalho (Antunes, 1999), e do seu trabalho, para a aproximação com o coletivo social, clamante de atenção e cuidado. Este coletivo vem reclamando da crescente sensação de desamparo $e$ desassistência e já é comum a crítica dos bilhões gastos numa assistência cada vez menos produtora de respostas suficientes e satisfatórias, embora sempre repleta de máquinas e tecnologia. Talvez por se perceberem envolvidos na armadilha produtora de falsa segurança pela tecnologia cada vez mais desnudada, mais e mais indivíduos têm buscado amparo em outras formas de cuidado, entre as quais o fortalecimento das práticas holistas $e$ até dos modismos 'alternativos'.

Ao mergulharmos junto com ela nesta crise, é preciso que não temamos o novo, como uma renegação do velho, e nem mesmo o diferente, como a emersão da novidade, abrindo-se, antes, para a produção de diversidade, em sendo diversidade. Para fazer isso, é preciso que busquemos, olhos e ouvidos atentos, semiológica e semioticamente, as incontáveis manifestações da

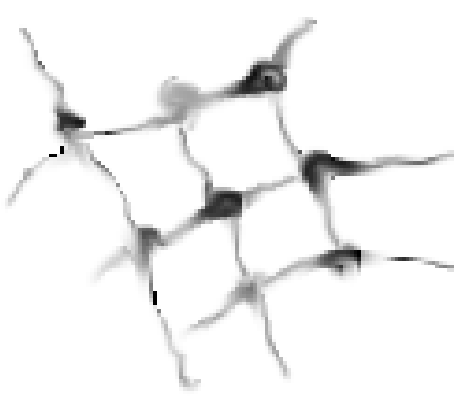


realidade, conhecendo-a, admirando-a e conquistando segurança em trilhá-la, para permitirmos o resgate do primevo papel da Medicina, e da clínica.

Tornados substitutos oficiais dos curandeiros, deles extraímos o místico $e$ o execramos. Ao fazê-lo, em seu lugar colocamos uma outra regra de autenticidade e de legitimidade, o estatuto científico do saber médico: estatuto, como vimos, de base positivista, cujas origens cartesianas apontam para um dualismo que separa radicalmente corpo e espírito e elabora uma abordagem antropológica essencialmente mecânica. Mas não podemos negar que a legitimação que encontravam advinha justamente do exercício cotidiano do saber ouvir, antecessor ao saber fazer; pelo exercício paciente do conhecimento (compreensivo) de sua comunidade. Além disso, sua não recusa em constantemente (re)aprender, não somente os fazia amigos do conhecimento como recebedores de uma validação social indiscutível!

Romper com as amarras do convencional biológico desalienando a clínica. Quebrar as velhas estruturas que cristalizam a alienação do trabalho. Esta é a dupla jornada a que devemos nos entregar na ampliação da prática médica, $e$ na retomada da significância do consultório. Ao fazê-lo, reconstruiremos o valor social da própria Medicina.

\section{Referências}

ACIOLE, G. G. Entre o cliente e o usuário: uma discussão do trabalho e da cultura médica no Brasil. Rev. Jovem Médico, v.4, n.2, p.103-6, 1999.

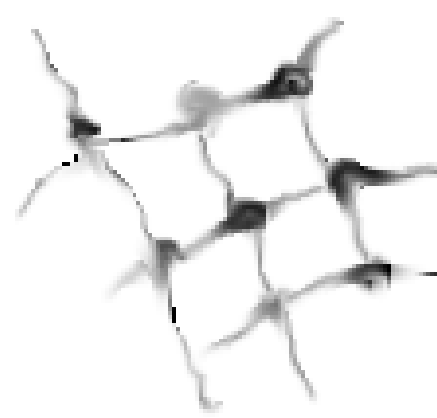

ACIOLE, G. G. Entre o estado e o mercado: apontamentos para uma discussão de "público" e de "privado" na saúde. Excerto de projeto de tese. Campinas: LAPA/DMPS/UNICAMP, 2000. Mimeografado.

ACIOLE, G. G. O ato médico em questão. Campinas: Núcleo de Estudos e Pesquisas em Saúde e Sociedade: trabalho médico, políticas públicas e reestruturação produtiva/SINDIMED - CR, 2003. Mimeografado.

ACIOLE, G. G.; MERHY, E. E. Uma nova escola médica é possível? Aprendendo com a CINAEM as possibilidades de construção de novos paradigmas para a formação em Medicina. Rev. Próposições, v.14, n.1(40), p.53-68, 2003.

ANTUNES, R. Centralidade do trabalho: a polêmica entre Lukács e Habermas In: Os sentidos do trabalho: ensaio sobre a afirmação e a negação do trabalho. São Paulo: Boitempo Editorial, 1999. p.135-65.

CAMPOS, G. W. S. Reforma da reforma: repensando a saúde. São Paulo: HUCITEC, 1992.

CAMPOS, G. W. S. Os médicos e a política de saúde: entre a estatização e o empresariamento. A defesa da prática liberal da Medicina. São Paulo: Hucitec, 1988.

CANGUILHEM, G. O normal e o patológico. 3.ed. Rio de Janeiro: Forense Universitária, 1990.

CECILIO, L. C. O.; MATSUMOTO, N. F. Uma taxonomia operacional das necessidades de saúde. Campinas: DMPS/FCM/UNICAMP, 2000. Mimeografado.

DONNANGELO, M. C. F. Saúde e sociedade. São Paulo: Livraria Duas Cidades, 1976.

FISCHER, E. A necessidade da arte. 9.ed. Rio de Janeiro: Guanabara, 1987.

FOUCAULT, M. O nascimento da clínica. 4.ed. Rio de Janeiro: Forense Universitária, 1994.

LUZ, M. T. Natural, racional, social: razão médica e racionalidade científica moderna. Rio de Janeiro: Campus, 1988. 
ACIOLE, G. G.

MARCUSE, H. O homem unidimensional. Rio de Janeiro: Paz e Terra, 1980.

MARCUSE, H. Razão e revolução: Hegel e o advento da teoria social. 4.ed. Rio de Janeiro: Paz e Terra, 1988

MARX, K. O Capital: crítica de economia política. São Paulo: Abril Cultural, 1983. (Coleção Os Economistas).

MENDES-GONÇALVES, R. B. Tecnologia e organização social das práticas de saúde: características tecnológicas do processo de trabalho na rede estadual de centros de saúde de São Paulo. 1986. Tese (Doutorado) - Faculdade de Medicina, Universidade de São Paulo, São Paulo.

MERHY, E. E. Crise no modo de se produzir saúde: uma discussão do modelo assistencial e o trabalho médico no Brasil. Campinas: SINDIMED, 1997a. Mimeografado.

MERHY, E. E. Revisitando a teoria do trabalho, em busca da desconstrução da visão neoliberal de "gerenciamento do cuidado": uma tarefa para o movimento sanitário. Campinas, 1997b. Mimeografado.

MERHY, E. E. Saúde: cartografia do trabalho vivo. São Paulo: HUCITEC, 2002.

SANTOS, R. C. Um ator social em formação: da militância à descrição e análise do processo de formação médica no Brasil. 1998. Dissertação (Mestrado) - Departamento de Medicina Preventiva e Social, Faculdade de Ciências Médicas, Universidade de Campinas, Campinas.

SANTOS, R. C. Em busca de caminhos para a construção de um novo saber fazer na clínica. Campinas: LAPA/DMPS/UNICAMP, 1999. Mimeografado.

SCHRAIBER, L. B. O médico e seu trabalho: limites da liberdade. São Paulo: HUCITEC, 1993

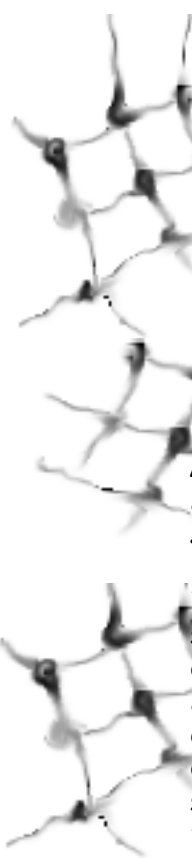

ACIOLE, G. G. El lugar, la teoría y la práctica profesional del médico: elementos para un abordaje crítico de la relación médico-paciente en el consultorio, Interface - Comunic., Saúde, Educ., v.8, n.14, p.95-112, set.2003-fev.2004.

Este trabajo plantea la discusión de la relación entre el médico y su paciente en tres de (sus elementos: a) el consultorio, como el lugar de la práctica médica; b) la racionalidad científico-biológica de su "saber hacer"; c) las cuestiones estructurales y coyunturales que aluden a los médicos. Proponiendo considerar esta relación como central para la práctica de la medicina, el autor argumenta que la superación de los límites colocados por esos elementos será alcanzada por medio de otra práctica profesional y por el alargamiento de sus bases teóricas, que constituyan otro valor y otro significado para el encuentro entre el médico y su paciente.

PALABRAS CLAVE: Relaciones médico-paciente; Medicina; salud; sociedades; conductas en la práctica de los médicos. 